\title{
Scabies Prevalence and Risk Factors in Pakistan: A Hospital Based Survey
}

\author{
Farhana Riaz Chaudhry ${ }^{1 *}$, Khalid Hameed ${ }^{1}$, Shumaila Naz ${ }^{1}$, Dilwar Annaritamolinar Min ${ }^{2}$, Paolotizzani ${ }^{3}$, \\ Abbas Rizvi ${ }^{3}$ and Luca Rossi ${ }^{3}$ \\ ${ }^{1}$ Department of Zoology, Pir Mehr Ali Shah Arid Agriculture University Rawalpindi, Pakistan
}

${ }^{2}$ Department of Dermatology, Military Hospital, Pakistan

${ }^{3}$ Department of veterinary sciences, University of Turin Italy

Received: December 23, 2017; Published: February 05, 2018

*Corresponding author: Farhana Riaz Chaudhry, Department of Zoology, Pir Mehr Ali Shah Arid Agriculture University Rawalpindi, Rawalpindi, Pakistan, Email: farhana_ahmer@yahoo.com

\begin{abstract}
In Pakistan, scabies is considered as common skin infestation but no comprehensive study is available on its epidemiology and risk factors associated with scabies. Tendency of emergence/reemergence attributes of scabies prompted to design one year study to evaluate the epidemiological profile of scabies infestation. Data was collected through questionnaires from patients visiting the Dermatology Clinic of the Military Hospital- Rawalpindi-Pakistan. The risk factors were analyzed through Chi square and later on processed through GLMs to see their impact on the scabies. Hospital based data revealed that scabies contribution is $38.15 \%$ among dermatological disorders. The infestation was higher in males than females ( 53.81 vs $24.22 \%$; $\mathrm{p}<0.05$ ) and early school going children were the most susceptible group for this disease (46.88\%; $\mathrm{p}<0.05$ ). The scabies was more common in urban population than rural one (46.46 vs 27.2\%; $\mathrm{p}<0.05$ ).A clear trend of seasonal pattern came on record with a highest infestation in winter (63.75\%) and lowest in summer (16.89\%).Analysis of risk factors explained $89 \%$ of variations in disease prevalence.The current study brought strong and influential features on record which is alarming for health professionals enforcing them to design effective control strategies and awareness campaigns to reduce scabietic infestation in human community.
\end{abstract}

Keywords: Sarcoptesscabiei; Itch mite; Infestation; Prevalence; Socio-Demographic Profile

\section{Introduction}

Scabies is a neglected contagious skin disease caused by the microscopic mite, Sarcoptesscabiei var. hominis [1]. The condition is worldwide distributed with an estimated incidence of 300 million cases per year Mimouniet [2]. Scabietic patients characteristically suffer from intense pruritus and scratching which occasionally lead to hyperkeratosis forms and secondary bacterial skin lesions [3]. The worse itching at night due to nocturnal activity of mites causes insomnia and restlessness which has negative impact on daily regular activities of patients [4]. The psychological complications due to shameful perception of this disease discourage affected individuals to seek medical attention and inform close contacts which should be also treated to ensure eradication [5]. The most effective means of transmission is direct skin to skin contact however indirect transmission via fomites is also effective especially in case of crusted scabies [2].

Recognized risk factors of scabies are close contact with an infested relative and acquired immune deficiencies for hyperkeratosis forms [6]. A range of other risk factors have been proposed, most of them being direct or indirect indicators of poverty at the community or infra-community level [7]. However, despite abundant literature on the epidemiology of scabies in developing countries $[3,7,8]$. The relative importance of the fore mentioned risk factors has been infrequently investigated. The present crosssectional interview based study, carried out in the Rawalpindi area, Pakistan, was designed to update and quantitatively substantiate previous epidemiological surveys in the Asia sub-continent, where hyper-endemic scabies still represents a major public health problem Malliket, Khan, Yasmin. [9].

\section{Methods}

\section{Study Area}

The present study was carried out in the Dermatology Department of the Military Hospital of Rawalpindi, Pakistan (DDMH) which provides assistance to the families of military 
personnel and to the general public. Patients admitted to DDMH originate from a large and predominantly urban area at the edge of the Pothwar plateau, south of the Margalla hills, with approximately 4.5 million inhabitants (centroid at $33.43^{\circ} \mathrm{N} 73.04^{\circ} \mathrm{E}$ ). The area is characterized by mild winters and hot summers, with monsoon rains occurring during July and August [10].

\section{Study Design}

DCMH was visited by the same operator for eight working days per month throughout the year. Data was acquired by interviewing all admitted patients. The self-developed questionnaire enclosed information on gender, age, residence, itching in close contacts, social habits, and the economic status of the patient. The patients were divided into seven age groups: preschool children ( $\leq 4$ years), first school children (5-9 years), pre-adolescents (10-14 years), adolescents (15-19 years), early adults (20-39 years), middle adults (40-59 years), and late adults ( $\geq 60$ years) according to [11]. The economic status of the patients was evaluated by the month family income in Pak rupees and divided into three categories: low (<15,000 Pak rupees/month), middle (15,000-50,000 Pak rupees/ month) and high ( $>50,000$ Pak rupees/month). All interviews were carried out by the same operator. For the purpose of this study, a case of scabies was identified based on the outpatient record (including clinical diagnosis and therapy) signed by dermatologist on duty at DDMH. As reported by collaborating dermatologists, skin scrapings were also taken on approximately one third of the suspected patients and processed according to standard techniques

\section{Results}

Table 1: Number of Patients by Age group and gender MODIFY TITLE, ENRICH

\begin{tabular}{|c|c|c|c|c|c|c|c|c|}
\hline \multirow{2}{*}{ Age group } & $\begin{array}{l}\text { Scabietic } \\
\text { patients }\end{array}$ & $\begin{array}{c}\text { Other } \\
\text { Patients }\end{array}$ & Chi square & $P$ value & \multirow[t]{2}{*}{ Chi square } & \multirow[t]{2}{*}{$P$ value } & \multirow[t]{2}{*}{ Odds ratio } & \multirow{2}{*}{$\begin{array}{c}\text { Confidential } \\
\text { interval }\end{array}$} \\
\hline & Males & Female & Male & Female & & & & \\
\hline$\leq 4$ years & 108 & 67 & 88 & 203 & 44.42 & $\mathrm{P}<0.05$ & 3.72 & $2.51-5.52$ \\
\hline 5-9 years & 69 & 74 & 50 & 112 & 9.65 & $\mathrm{P}<0.05$ & 2.08 & $1.31-3.33$ \\
\hline $10-14$ years & 29 & 32 & 30 & 88 & 8.90 & $\mathrm{P}<0.05$ & 2.66 & $1.39-5.10$ \\
\hline $15-19$ years & 81 & 7 & 40 & 71 & 64.61 & $\mathrm{P}<0.05$ & 20.54 & $8.66-48.73$ \\
\hline $20-39$ years & 115 & 44 & 119 & 206 & 54.52 & $\mathrm{P}<0.05$ & 4.52 & $2.99-6.85$ \\
\hline $40-59$ years & 113 & 54 & 141 & 150 & 15.85 & $\mathrm{P}<0.05$ & 2.23 & $1.50-3.31$ \\
\hline$\geq 60$ years & 84 & 25 & 46 & 118 & 8.61 & $\mathrm{P}<0.05$ & 8.61 & $4.91-15.11$ \\
\hline Total & 599 & 303 & 514 & 948 & 218.66 & $\mathrm{P}<0.05$ & 3.65 & $3.06-4.34$ \\
\hline
\end{tabular}

Data were collected from 2364 patients. Among them 902(38.15\%) were diagnosed with scabies, indicating that Sarcoptes infestation is largely prevalent in the area. Analysis of risk factors is illustrated in Table 1. A significantly higher prevalence of scabies was reported in males than in females (53.81 vs $24.22 \%$; $\left.\chi^{2}=218.75, \mathrm{p}<0.05\right)$. As regards age, the only higher risk category were early school children (46.88\%; $\left.\chi^{2}=11.31, \mathrm{p}<0.05\right)$, whereas early adults were relatively less exposed (32.85\%; $\chi^{2}=7.26$, $\mathrm{p}<0.05$ ). Scabies occurred more frequently in male than in female individuals in all age groups (Table 2). Scabies was more prevalent in winter $\left(63.75 \% ; \chi^{2}=366.54, \mathrm{p}<0.05\right)$ and relatively rare in summer $\left(16.90 \% ; \chi^{2}=147.20, p<0.05\right)$, and it was more common in patients originating from urban vs rural areas (46.46 vs $27.2 \% ; \chi^{2}=90.94$,
[12]. To confirm the diagnosis. However, results of skin scrapings were not made available.

\section{Statistical Analysis}

Chi square analysis was used as a test of significance for all epidemiological factors (gender, age, residence, itching in household, season, sharing and economic status) on Epi InfoTM 7 (Centers for Disease Control, Atlanta, GA, USA). With reference to age and economic status they were classified into seven and three categories respectively so chi square analysis was performed for each category separately comparing patients of that category with all others. The strength of association of each epidemiological factor with disease was estimated through odds ratio and the corresponding 95\% confidential intervals. All the significant epidemiological factors were later on processed through Generalized Linear Model (GLM) with binomial distribution in R program ( $\mathrm{R}$ core team, 2014) and the coefficient of determination R2 was calculated. All the explanatory variables (epidemiological factors) in GLM were tested against the response variable i.e. presence or absence of scabies. Scabies patients were included in infected group while patients diagnosed for any other disease were considered as controlled group. The models with and without interactions were tested for the best model. The epidemiological factors and interactions which were not significantly contributing to the variations in disease were removed from the model. The model selection was made through the evaluation of AIC value and model with lowest AIC value was selected. $P$ value less than 0.05 was taken as significant. $\mathrm{p}<0.05) .98 .49 \%$ patients reported infection in close contacts $\left(\chi^{2}=2081, \mathrm{p}<0.05\right)$. The patients admittedly sharing household accessories (beds, towels, clothes) were more frequently affected than patients which were not used to share them (63.75 vs $4.59 \%$; $\left.\chi^{2}=860.82, p<0.001\right)$. Finally, the highest prevalence of scabies was recorded in the lowest income group $\left(53.28 \% ; \chi^{2}=220.08, p<0.05\right)$. All the significant epidemiological factors in the univariate analysis were processed through General Linear Models (GLMs), the most performant of them including six risk factors, namely gender, residence, infection in close contacts, sharing of bed, clothes and towels, season and the economic status. The model explained $89 \%$ of the observed variation (Table 3). 
Table 2: Demographic Profile of Scabies Patients MODIFY TITLE, ENRICH CAPTIONS.

\begin{tabular}{|c|c|c|c|c|c|c|c|}
\hline Characters & Categories & Scabieticpatients & Other Patients & Chi Square & $p$ value & Odds Ratio & $\begin{array}{l}\text { Confidence } \\
\text { Interval }\end{array}$ \\
\hline \multirow{7}{*}{ Age } & PS & 175 & 291 & 0.089 & $\mathrm{p}>0.05$ & 0.97 & $0.79-1.19$ \\
\hline & FS & 143 & 162 & 11.31 & $\mathrm{P}<0.05$ & 1.51 & $1.19-1.93$ \\
\hline & $\mathrm{PA}$ & 61 & 118 & 1.36 & $\mathrm{p}>0.05$ & 0.82 & $0.60-1.14$ \\
\hline & A & 88 & 111 & 3.39 & $\mathrm{p}>0.05$ & 1.32 & $0.98-1.76$ \\
\hline & EA & 159 & 325 & 7.26 & $\mathrm{P}<0.05$ & 0.75 & $0.61-0.92$ \\
\hline & MA & 167 & 291 & 0.69 & $\mathrm{p}>0.05$ & 0.91 & $0.74-1.13$ \\
\hline & LA & 109 & 164 & 0.41 & $\mathrm{p}>0.05$ & 1.08 & $0.84-1.41$ \\
\hline \multirow{2}{*}{ Residence } & Urban & 624 & 719 & 90.94 & $\mathrm{p}<0.05$ & 2.31 & $1.95-2.76$ \\
\hline & Rural & 278 & 743 & & & & \\
\hline \multirow{2}{*}{$\begin{array}{l}\text { Itching in } \\
\text { close contacts }\end{array}$} & Yes & 846 & 13 & 2081 & $\mathrm{P}<0.05$ & 683.86 & 915.53-3097.01 \\
\hline & No & 56 & 1449 & & & & \\
\hline \multirow{2}{*}{ Sharing } & Yes & 855 & 486 & 860.82 & $\mathrm{p}<0.05$ & 36.53 & $26.71-49.96$ \\
\hline & No & 47 & 976 & & & & \\
\hline \multirow{4}{*}{ Season } & Winter & 540 & 307 & 366.54 & $\mathrm{p}<0.05$ & 5.61 & $4.67-6.74$ \\
\hline & Monsoon & 112 & 353 & 48.56 & $\mathrm{p}<0.05$ & 0.44 & $0.35-0.56$ \\
\hline & Post Monsoon & 152 & 320 & 8.85 & $\mathrm{p}<0.05$ & 0.72 & $0.58-0.89$ \\
\hline & Summer & 98 & 482 & 147.20 & $\mathrm{p}<0.05$ & 0.25 & $0.19-0.31$ \\
\hline \multirow{3}{*}{$\begin{array}{c}\text { Economic } \\
\text { Status }\end{array}$} & Low & 617 & 541 & 220.08 & $\mathrm{p}<0.05$ & 3.68 & $3.09-4.39$ \\
\hline & Middle & 235 & 549 & 33.27 & $\mathrm{p}<0.05$ & 0.58 & $0.49-0.70$ \\
\hline & High & 50 & 372 & 150.66 & $\mathrm{p}<0.05$ & 0.17 & $0.13-0.23$ \\
\hline
\end{tabular}

PS: Pre-School, FS: First School Children, PA: Pre-Adolescent, A: Adolescent, EA: Early Adults, MA: Middle Adults, LA: Late Adults Table 3: Generalized Linear Model for the Analysis of Risk Factors associated with scabies.

\begin{tabular}{|c|c|c|c|c|c|}
\hline \multicolumn{2}{|c|}{ Coefficients } & Estimate Std. & Std. Error & $Z$ value & p Value \\
\hline \multicolumn{2}{|c|}{ Intercept } & -7.84 & 0.74 & -10.63 & $\mathrm{p}<0.05$ \\
\hline \multicolumn{2}{|c|}{ Gender Male } & 2.31 & 0.36 & 6.36 & $\mathrm{p}<0.05$ \\
\hline \multicolumn{2}{|c|}{ Residence Urban } & 0.16 & 0.33 & 0.50 & $\mathrm{p}>0.05$ \\
\hline \multicolumn{2}{|c|}{ Itching in close contact } & 8.27 & 0.56 & 14.67 & $\mathrm{p}<0.05$ \\
\hline \multicolumn{2}{|c|}{ Sharing } & 3.20 & 0.44 & 7.30 & $\mathrm{p}<0.05$ \\
\hline \multirow[t]{3}{*}{ Season } & Post Monsoon & 0.02 & 0.47 & 0.050 & $\mathrm{p}>0.05$ \\
\hline & Summer & -2.93 & 0.63 & -4.68 & $\mathrm{p}<0.05$ \\
\hline & Winter & 0.85 & 0.42 & 2.00 & $\mathrm{p}<0.05$ \\
\hline \multirow[t]{2}{*}{ Economic status } & Low & 1.82 & 0.50 & 3.67 & $\mathrm{p}<0.05$ \\
\hline & Middle & 0.21 & 0.52 & 0.41 & $\mathrm{p}<0.05$ \\
\hline
\end{tabular}

Null deviance: 3143.27 on 2363 degrees of freedom, Residual deviance: 355.18 on 2356 degrees of freedom, AIC: 375.18, R2 value= 0.887

\section{Discussion}

The high prevalence of scabies amongst dermatologic patients in this study confirms its persisting endemic status in Pakistan. In previous studies with a similar design, prevalence ranged between 18.1 and $70.2 \%$ of the dermatologic caseload $[9,13,14]$. In the neighboring Bangladesh, scabies was reported in $98 \%$ of investigated schools [15]. The higher prevalence of scabies in males has been previously attributed to different lifestyle, implying greater exposure to potential mite sources e.g. due to more intense social life in the community and the working periods far from their households [2,9,15-18]. However, there are studies showing no sexrelated differences $[19,20]$. And other studies reporting higher odds of infestation in females [21-23]. Interestingly, stratification of the prevalence data by sex and age in this survey showed that scabies was more prevalent in males since the youngest age classes, when differences in lifestyle are clearly far to be applicable justification. We have no explanation for the observed differences, though we may suspect an occult culture related bias.

The higher prevalence of scabies in first school children is not surprising, since schools - a group setting in which people with different epidemiological background are in close contact and share supplies and equipment - are known to inherently foster the transmission of several infections [http://www.cdc.gov/ healthyyouth/infectious/]. On the other hand, the limited range of the odds in Table 1 suggests that the investigated age-related 
differences were not remarkable, and that age groups in this study were almost equally susceptible to scabies, with negligible if any role for herd immunity. This is consistent with studies conducted in Pakistan [9], Brazil [20]. And the West Bank, Palestinian Territories [19]. Similarly to [22-25]. Scabies was more prevalent in winter. During this season, fertility of the mites - determined by the number of eggs in the mite burrow - is reportedly higher [26] And their off-host survival is enhanced by the higher humidity and lower temperature $[7,8,22]$. Moreover, increased physical crowding of individuals during the cold season may contribute to seasonality of scabies [26].

No or little seasonal difference was found in study areas with less contrasted climate $[11,20]$. Crowding may also justify the higher prevalence of scabies in urban vs rural patients, which is consistent with findings in Brazil, where scabies was twice as prevalent in a densely populated urban slum as in a rural community where families lived in larger spaces [20]. And in UK [24]. In contrast, prevalence was higher in rural vs urban settings in Poland, due to lower social and material status of the rural communities and their hampered access to the medical services [22]. As expected $[3,8,18]$. Infection in close contacts was by far the single most significant risk factor, suggesting that the large majority of scabietic patients were directly or indirectly (via fomites) infected by other family members and/or housemates. Coupled with the high prevalence of the disease in the studied population, it calls for the necessity of fomite precautions and of treatment of asymptomatic family members and physical contacts of all cases of scabies [27]. And the awareness still to raise on its principal transmission patterns. Interestingly, a recent interview study amongst general medical practitioners (GMPs) in Pakistan have demonstrated a diffuse "lack of knowledge regarding various aspects of scabies" and recommended an active intervention to improve their awareness, so that scabies will be identified and treated appropriately and valuable information will be provided to patients and communities [28].

The complex relationships between low socioeconomic status, overcrowding, risk behavior, proportion of individuals infested, and the spread of S. scabiei in the developing world have been clearly addressed in the recent literature $[11,14,15,29]$. In this study, evidence showed that scabies was remarkably more prevalent amongst lower income groups, and that risk behavior, namely sharing of household items, was also more common in these cohorts. Though other aspects were not specifically investigated in our questionnaires, we hypothesize that poverty in the study area may also mirror on awareness (e.g: ignorance of the disease until it becomes a major threat at the family level), stigma associated with the disease, and the restricted access to health care, which delays diagnosis and jeopardize the efficacy of treatment. Generalized Linear Model (GLM) was used to estimate the contribution of epidemiological factors to the variations in disease. The epidemiological factors in this study were able to explain $89 \%$ of variations. We did not find any significant interactions as each epidemiological factor was independent for its contribution in disease. There were many biased in study as it was conducted only in dermatology, hospital was in urban area and data of all patients was not collected due to survey in eight working days in a month. A broad comprehensive population based study with more epidemiological and climatic factors should be designed to extend our knowledge of risk factors associated with scabies.

\section{Conclusion}

The high prevalence of scabies in the study area calls for programs to control this neglected disease and public health problem in the general population, with a special attention to poor communities. Programs should integrate the availability of effective and user friendly pharmacological treatments with efforts to improve the socioeconomic conditions, and specific education programs [29]. Suggested targets of the last ones are:

i. First school children, a risk category who may convey valuable first-hand information to their families;

ii. GMPs, who are more ready available than skin specialists and, often, the sole option for poor people living far from large towns. Epidemiological studies addressing poverty-related risk factors in more detail would also be desirable.

\section{Acknowledgement}

The authors thank to Higher Education Commission-Islamabad, Pakistan for financial support under 5000 indigenous fellowship program. The authors declare that there is no conflict of interest.

\section{References}

1. Arlian LG (1989) Biology, host relations and epidemiology of Sarcoptes scabiei. Annual Review Entomology 34: 139-161.

2. Hengge UR, Currie BJ, Jäger G, Lupi O, Schwartz RA (2006) Scabies: a ubiquitous neglected skin disease.The Lancet Infectious Diseases 6: 769-79.

3. Chosidow 0 (2006) Epidemiological Pattern of Scabies and Its Social Determinant Factors in West of Iran. New England Journal of Medicine 354: 1718-1727.

4. Buffet M, Dupin N (2003) Current treatments for scabies. Fundamental \& Clinical Pharmacology 17: 217-225.

5. McCarthy JS, Kemp DJ, Walton SF (2004) Scabies: more than just an irritation. Postgraduate Medical Journal 80: 382-387.

6. Currie BJ, Harumal P, McKinnon M, Walton SF (2004) First documentation of in vivo and in vitro ivermectin resistance in Sarcoptesscabiei. Clinical Infectious Diseases 39(1): 8-12.

7. Hay RJ, Steer AC, Engelman D, Walton S (2012) Scabies in developing world-its prevalence, complications, and management. Clinical Microbiology and Infection 18: 313-323.

8. Hicks MI, Elston DM (2009) Scabies. Dermatologic Therapy 22: 279-292.

9. Ursani NM, Baloch GH (2009) Scabies epidemic at Tando Muhammad Khan, Sindh. Journal of Pakistan Association of Dermatologists 19: 8689.

10. Adnan S, Mahmood R, Khan AH (2009) Water Balance Conditions in Rainfed Areas of Potohar and Balochistan Plateau During 1931-08. World Applied Science Journal 7(2): 162-169.

11. Feldmeier H, Jackson A, Ariza L, Calheiros CML, Soares VL, et al. (2008) The epidemiology of scabies in an impoverished community in rural Brazil: Presence and severity of disease are associated with poor living conditions and illiteracy. Journal of the American Academy of Dermatology 60: 436-443. 
12. Granholm JM, Olazewski J (2005) Scabies prevention and control manual.Michigan Department of Community Health.

13. Memon KN, Soomro RA, Ansari MS (2011) Pattern of skin diseases in patients visiting a tertiary care health facility at Hyderabad, Pakistan. JournalAyub Medical College Abbottabad 23(4): 37-39.

14. Raza N, Qadir SNR, Agha H (2009) Risk factor for scabies among male soldiers in Pakistan: case control study.Eastern Mediterranean Health Journal 15(5): 1105-1110.

15. Karim SA, Anwar KS, Khan MAH, Mollah MAH, Nahar N (2007) Sociodemographic characteristics of children infested with scabies in densely populated communities of residential madrashas (Islamic education institutes) in Dhaka, Bangladesh. Public Health 121: 923-934.

16. Otero L, Varela JA, Espinosa E (2004) Sarcoptes scabiei in a sexually transmitted infections unit: a 15 -year study. Sexually Transmitted Diseases 31: 761-765.

17. Marrone R, Vignally P, Rosso A, Didero D, Pizzini E (2012) Epidemiology of Skin Disorders in Ethiopian Children and Adolescents: An Analysis of Records from the Italian Dermatological Centre, Mekelle, Tigray, Ethiopia. Pediatric Dermatology 29(4): 442-447.

18. Al-Musawi MM, Hasan HR, Maluki AH (2013) Prevalence of Scabies among Patients Attending the Dermatology Outpatient Clinic in Najaf governorate Iraq. Journal of Advanced Medical Research 3(4): 63-70.

19. Amro A, Hamarsheh O (2012) Epidemiology of scabies in the West Bank, Palestinian Territories (Occupied). International Journal of Infectious Diseases 16: 117-120.

20. Heukelbach J, Wilcke T, Winter B, Feldmeier H (2005) Epidemiology and morbidity of scabies and pediculosiscapitis in resource-poo communities in Brazil. British Journal of Dermatology 153: 150-156.
21. Hassan HA, Ezzat W, Lebshtein A (1979) Scabies as a health problem among primary school children in Cairo. Journal of Egyptian Public Health Association 54: 65-75.

22. Buczek A, Pabis B, Bartosik K, Stanislawek IM, Salata M, et al. (2006) Epidemiological study of scabies in different environmental conditions in central Poland. Annals of Epidemiology 16: 423-428.

23. Lassa S, Campbell MJ, Bennett CE (2011) Epidemiology of scabies prevalence in the U.K. from general practice records.The British Journal of Dermatology 164(6): 1329-1334.

24. Downs AMR, Harvey I, Kennedy CTC (1999) The epidemiology of head lice and scabies in the UK. Epidemiology\&Infection 122: 471-477.

25. Mimouni D, Ankol OE, Davidovitch N (2003) Seasonality trends of scabies in a young adult population: a 20-year follow-up. British Journal of Dermatology 149: 157-159.

26. Sokolova TV, Radchenko MI, Lange AB (1989) The seasonality of scabies morbidity and the fertility of the itch mite Sarcoptesscabiei de Geer as an index of the activity of a population of the causative agent. VestnikDermatologii I Venerologii 63(11): 12-25.

27. Burkhart CG, Burkhart CN, Burkhart KM (2000) An epidemiologic and therapeutic assessment of Scabies. Cutis 65: 233-240.

28. Rathi SK, Rathi HS, Lakhani H, Hansotia MF (2001) Awareness about scabies among general medical practitioners (GPs) of Karachi, Pakistan. Journal Pakistan Medical Association 51(10): 370-2.

29. Heukelbach J, Feldmeier H (2006) Scabies. The Lancet 367 (9524): 1767 1774.
This work is licensed under Creative Commons Attribution 4.0 License

Submission Link: http://biomedres.us/submit-manuscript.php

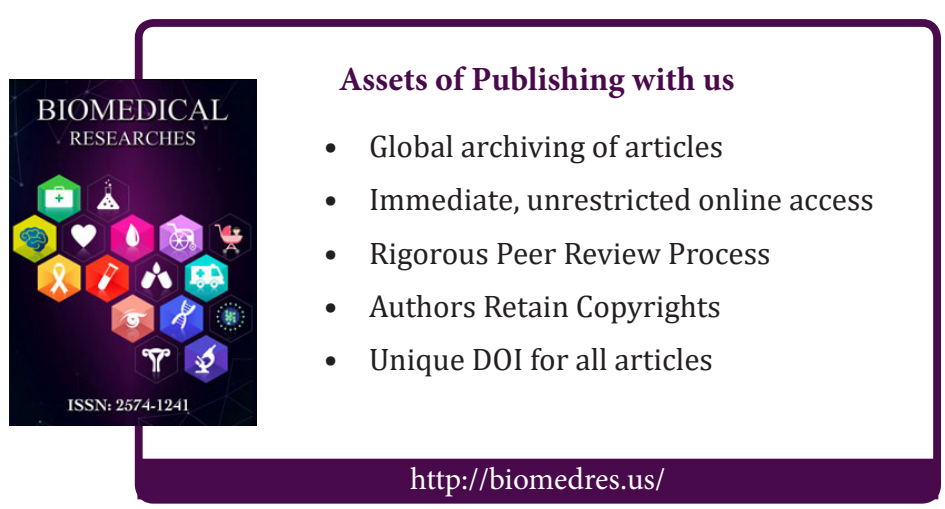

